\title{
Thyroid Dysfunction in Type 1 Diabetes Mellitus in an Iranian Elderly Woman
}

\author{
Mohadese Nemati ${ }^{1}$, Elmira Roshani Asl ${ }^{1}$, Venus Haghshenas ${ }^{2}$, Siamak Rashidi ${ }^{3}$, \\ Zohre Ahmadi ${ }^{4}$, Bohran Taushih ${ }^{3}$
}

${ }^{1}$ Department of Biochemistry, Faculty of Medicine, Urmia University of Medical Sciences, Urmia, Iran. ${ }^{2}$ Kurdistan Azad University, Sanandaj, Iran. ${ }^{3}$ Tohid Hospital, Kurdistan University of medical sciences, Sanandaj, Iran. ${ }^{4} \mathrm{MSc}$ student of health education and health promotion,faculty of health,Qom university of Medical sciences ,Qom, Iran.

\begin{abstract}
Objective: Type 1 Diabetes mellitus (T1DM) and thyroid dysfunction consider as main metabolic and endocrine disorders. In previous studies, individuals with T1DM were susceptible to Thyroid disorders. The prevalence of clinical and subclinical Thyroid dysfunction have noticeable importance especially regarding women and their related stigma. Methods: The presented survey, a case-control study evaluated the thyroid dysfunction among T1DM elderly women referred to diabetes clinic of Tohid Hospital in Sanandaj city. The whole blood samples were attained from all individuals and then the following tests were done: fasting blood-sugar (FBS), Serum TSH, anti-Thyroperoxidase (Anti-TPO) and Free T4. Results: The prevalence of Thyroid disorder in examined patients was 17 percent and autoimmune Thyroid dysfunction disorder, that examined by positive test-result of Anti-TPO showed up in 10.2 percent of patients. Prevalence of sub-clinical Hypothyroidism was 13.2 percent; the clinical Hypothyroidism were 7.3 percent. Based on our data 2.9 percent of T1DM have subclinical Hyperthyroidism and 1.4 percent have clinical Hyperthyroidism. In our study, increased TSH level and existence of Anti-TPO in TIDM patients might be regarded as an additional TIDM problem in studied disease. Conclusion: This study confirmed the association between autoimmune Thyroid dysfunction (based on positive Serum-test of Anti-TPO) and T1DM.
\end{abstract}

Keywords: Type 1 Diabetes mellitus (T1DM)- thyroid dysfunction- elderly women- Sanandaj city

Asian Pac J Cancer Care, 4 (1), 15-18

\section{Introduction}

Diabetic patients are at higher risk for certain diseases than non-diabetics; Among all types all diseases cancer has always been the most important [1]. In a number of studies, there is a possible link between diabetes and an increased risk of certain cancers, but the results are very scattered But the biological connection of these two diseases is very complicated and still not well understood. According to studies, there is a relationship between type 2 diabetes and some types of cancer such as breast cancer, uterine wall cancer, liver, bladder, colorectal and pancreas. However, there was no increase in the risk of developing other types of cancer in many people with diabetes. Findings show that some aspects of diabetes are a risk factor for cancer. Currently, a factor that is more important than
Submission Date: 09/13/2018Ａcceptance Date: 11/15/2018

other aspects of this relationship is the lifestyle factor that affects diabetes-obesity, physical inactivity, sedentary lifestyles, and bad nutritional behaviors. These factors make changes that affect the risk of cancer. The most important thing is that these factors increase the amount of insulin in the blood, Insulin, in addition to its effect on sugar metabolism, is known as a growth factor and can stimulate the growth of pre-cancerous and cancerous cells. By assessing available articles and studies, there was no clear evidence of the impact of diabetes drugs on the increased risk of cancer. Only some studies on metformin and a possible reduction in the risk of cancer and even the improvement of the prognosis of certain cancers, especially breast cancer, have been mentioned. Drugs can be used to treat cancer using nanoparticles [2-3]. Nanoparticles have many uses, such as medicine

Corresponding Author:

Dr. Siamak Rashidi

Kurdistan Azad University, Sanandaj, Iran.

Email: Rashidi.semko83@gmail.com 
and industry [4-5]. Different nanoparticles are used in drug delivery, for instances, liposomal nanoparticles Niosomal nanoparticles and Nano-Poly Butyl Cyanoacrylate [6-11]. As mentioned Diabetic patients also face thyroid dysfunction more than other individuals of the society. Both diabetes and thyroid dysfunction (TD) consider as main metabolic and endocrine disorders. On the other hand, the patients suffering from an autoimmune disease might be exposed to other autoimmunity diseases. Type 1 Diabetes mellitus (T1DM) is also an autoimmune disease. Thyroid disorder is more common in women than men. Women which affected by T1DM are more susceptible to TD compared to non-diabetic individuals [12-13]. The association of diabetes mellitus (DM) and TD was first examined in previous decades [14-15]. Autoimmune thyroid dysfunction (ATD) is associated with T1DM. The symptoms of hyperthyroidism within T1DM individuals might cause symptoms like weight loss in spite of increase of appetite, fatigue and so on. [12,13, 16-18]. The incidence of TD among patients with DM had varied ranges in different countries .some studies reported that the considerable percent of women are afflicted with TD. Thyroid disorder is dependent on sex, age and ethnicity of patients. The extent of inflammation in Thyroid glands in women afflicted with T1DM had various degrees [17,19-29]. The relationship between thyroid dysfunction and T1DM is seems so complex and these associations affected by biochemical interactions. Indeed, clinical disorders in T1MD patients might be present without clinical symptoms. Based on author knowledge, it is necessary to define prevalence of clinical and sub-clinical thyroid dysfunction among T1DM patients especially women in our country. The aim of present study is defining TD prevalence in T1DM patients focusing on Iranian elderly women.

\section{Materials and Methods}

This case-control study conducted among TIDM patients who were referred to clinic diabetes of Tohid hospital in Sanandaj (west of Iran) during 2011-2012. The average age of diabetic patients were $52.2 \pm 2.9$ years that already diagnosed as TIDM for more than one year. The control group included mature and healthy women without T1DM with average age of 49/4 $\pm 3 / 2$ years. The socio-demographic characteristics showed no significant difference between two groups. 12-hour overnight fasting was necessary for getting blood sample for measuring Fasting blood sugar (FBS). Blood sample were collected and serum were isolated (The serum samples from 68 patients of T1DM and 122 healthy individuals). Diagnosis parameters in patient group were done based on clinical symptoms like weight loss, Polyuria and polydipsia, overeating, and Insulin injection for more than one year.

Samples were analyzed for measuring FBS, Serum TSH, Anti-TPO and Free T4 by ELISA kit (Accu-Bind, USA). Amounts higher than $40 \mathrm{u} / \mathrm{mL}$ were regarded as positive for Anti-TPO. For measurement of TSH, CLIA microwells kit (Monobind, USA)were used which its normal amount was around 0.4-5.45 $\mathrm{micu} / \mathrm{mL}$.

The following biochemical characteristic of thyroid disorder observe in clinical and subclinical hypothyroidism: amount of TSH is $>4.20 \mathrm{mIU} / \mathrm{mL}$ in both clinical and subclinical hypothyroidism. Amount of FT4 is $<0.93 \mathrm{ng} / \mathrm{dl}$ and $0.93-1.7 \mathrm{ng} / \mathrm{dl}$ in clinical and subclinical hypothyroidism respectively.

subclinical hyperthyroidism is so that TSH level was less than $0.27 \mathrm{mIU} / \mathrm{mL}$ and FT4 levels more than $1.7 \mathrm{ng} / \mathrm{dl}$ for FreeT4 level.

Autoimmunity with anti-TPO was diagnosed to be more than $34 \mathrm{IU} / \mathrm{mL}$ [22-29]. Statistical analysis were done by SPSS (version 21). The results were reported in mean \pm SD format and comparison of two groups done through Chi-Square and T-test. Significance level were considered as $\mathrm{P}<0.05$.

\section{Results}

The average age for T1DM individuals were $52 \pm 2.4$ years and $49.4 \pm 3.2$ years for case and control groups respectively. biochemical and demographic feature of studied population were shown in Table 1. Prevalence of TD in all diabetic patients was 17 percent. Autoimmunity with anti-TPO was reported as positive in 10.2 percent of patients. In T1DM individuals, prevalence of Subclinical and clinical hypothyroidism were 13.2 and 7.3 percent respectively. the prevalence of Subclinical and clinical hyperthyroidism were 2.9 and 1.4 percent respectively. In control group, the frequency and number of Subclinical and Clinical hypothyroidism were $1.6 \%$. Results shown in Table 2.

The information shows that TSH was apparently increased among patients and anti-TPO showed to exist in 6 out of 68 cases in T1DM patients. The increase in TSH and existence of Anti-TPO in patients was more common

Table 1. Demographic and Biochemical Characteristics of the Study Subjects

\begin{tabular}{lccc}
\hline Parameters & T1DM & Controls & P Value \\
\hline Number of participants & 68 & 122 & - \\
Age, years & $52 / 6 \pm 2 / 9$ & $49 / 4 \pm 3 / 2$ & NS \\
TSH $(\mathrm{mIU} / \mathrm{ml})$ & $2.69 \pm 2.39$ & $1.46 \pm 0.66$ & 0.001 \\
Free T4 & $0.74 \pm 0.13$ & $0.98 \pm 0.11$ & 0.001 \\
Fasting blood glucose, $\mathrm{mg} / \mathrm{dl}$ & $160.2 \pm 4.6$ & $78.9 \pm 9.1$ & 0.001
\end{tabular}

Data are expressed as mean \pm standard deviation; TSH, Thyroid stimulating Hormone

Table 2. The Frequency of Thyroid Dysfunction and Thyroid Autoimmunity in Subjects and Controls

\begin{tabular}{lccc}
\hline TD & $\begin{array}{c}\text { Cases } \\
(\mathrm{N}=68)\end{array}$ & $\begin{array}{c}\text { Controls } \\
(\mathrm{N}=122)\end{array}$ & P value \\
\hline Hypothyroidism & $5(7.3)$ & $2(1.6)$ & \\
Subclinical hypothyroidism & $9(13.2)$ & 0 & $>0.05$ \\
Subclinical hyperthyroidism & $2(2.9)$ & $2(1.6)$ & $>0.05$ \\
Hyperthyroidism & $1(1.4)$ & $2(1.6)$ & $\mathrm{NS}$ \\
Sero-positive for anti-TPO & $6(10.2)$ & $1(0.81)$ & $>0.05$ \\
\hline
\end{tabular}

NS, Not significant; Anti TG, AntiThyroid peroxidase; TD, Thyroid dysfunction 
than control group.

\section{Discussion}

Among different types of human disorders, such as cancers, and metabolic diseases [30-37] diabetes could be considered as one of the furthermost significant illness [31]. The aim of present study was to examine the existence of TD in elderly women with T1DM in comparison with control group (wholly constituted of female subjects). Almost one third of patients with T1DM had Thyrioid dysfunction or suffered from thyroid disorders. This issue can be justified in such a way that T1DM was an autoimmune disease and those with such a autoimmune disease are susceptible to other diseases of the same kind [24-26]. Thyroid diseases and TD are more common among women and also T1DM females may be more susceptible to TD compared to healthy female subjects [13,14-29]. The extent of inflammation in diabetic females especially those with TIDM seems to be more than healthy non-diabetic females. This will confirm this hypothesis that in type-one diabetic individuals the frequency of thyroid disorders is more [14-23].

TD might be without symptoms and these stigma may be sometimes misdiagnosed [27-28]. Our study confirms this fact that in the studied samples, the major percent of T1DM patients had subclinical TD. Sub-clinical hypothyroidism was a dysfunctional disorder observed in a significant percentage of studied patients which constituted 13.2 percent of T1DM individuals alike to the information of other studies [15-24]. Prevalence of anti-TPO in T1DM patients was considered as positive results which shown in noticeable percent of T1DM patients.

In present study, the average age of patients with positive Serum anti-TPO were more than patients with negative Anti-TPO. This issue is significant because these patients with clinical hyperthyroidism had a higher average age than other patients and this issue was confirmed in our study. In fact, sub-clinical thyroid disorders were made due to biochemical changes without any clinical symptoms.

In conclusion, results show this fact that functional TD might be present with T1DM. In fact, altered levels of TSH and existence of anti-TPO might be mentioned as a problem for diabetic patients. Our study showed the association between autoimmune hypothyroidism and T1DM especially in those with positive serum regarding anti-TPO, so it is better to check these patients annually for diagnosis of TD. The screening programs for T1DM female patients would be decreases progression of subclinical TD and thyroid. High prevalence of both diseases and existence of TD among T1DM might necessitate this investigation.

\section{Acknowledgments}

We are thankful to Tohid hospital diabetes clinic laboratory workers and Mr.seifi from tohid hospital. we also appreciate from support of Mr. Semko Rashidi.

\section{References}

1. Ebrahimi Far M, Hasanzade Ganroudsari M, Kazemi M, et al (2017). Enhancing Effects of Curcumin on Cytotoxicity of Paclitaxel, Methotrexate and Vincristine in Gastric Cancer Cells. Asian Pac J Cancer Prev, 18, 65-68.

2. Azizi $\mathrm{H}$,et al. The risk of colorectal cancer in type 2 diabetic patients. Medical Journal of Tabriz University of Medical Sciences \& Health Services. Oct/Nov2016, Vol. 38 Issue 4, p56-65. 10p.

3. Fatahi S, Afsari A, Fakhri M, Bijan S. The association between type 2 diabetes and the incidence of breast cancer. International Congress on Breast Cancer2011.

4. Mohammadi H, Abedi A, et al. Evaluation of synthesized platinum nanoparticles on the MCF-7 and HepG-2 cancer cell lines. International Nano Letters. 2013;3(1):1-5.

5. Izadi M, Ebrahimi Far M, Kanaani L, et al (2016). Remove Nickel (II) From Drinking Water Using Thiol-Functionalized Chitosan. Advanced Biomedical Research, 7, 107-112.

6. Khalili M, Akbarzadeh A, et al. The effect of nanoliposomal and PE gylated nanoliposomal forms of 6-gingerol on breast cancer cells. Research Journal of Recent Sciences. 2009;2277:2502.

7. Esfahani MKM , et al. Pegylation of nanoliposomal paclitaxel enhances its efficacy in breast cancer. Tropical Journal of Pharmaceutical Research. 2014;13(8):1195-8.

8. Ahmadi L, Chiani M, et al. To evaluate the effect of formulation of Nanoarchaeosomal 6-gingerol on the growth of breast cancer MCF-7 cell line. New Cellular and Molecular Biotechnology Journal. 2015;5(19):47-52.

9. Zarei M, Norouzian D, Chiani M, Ebrahimi H, Mohammad M, Akbarzadeh A. Advantages of paclitaxel-loaded nano niosomes to nanoliposomal formulation: an in vitro study. Int J Life Sci Bt \& Pharm Res. 2013;2:335-42.

10. Kanaani L, Javadi I, Ebrahimi Far M, Ebrahimi shahmabadi $\mathrm{H}$, et al (2017). Effects of cisplatin-loaded niosomal nanoparticles on BT-20 human breast carcinoma cells. Asian Pac J Cancer Prev, 18, 365-368.

11. Dadgar N, Alavi E, Moftakhari Esfahani M, et al. Evaluation the cytotoxicity of nanoliposomal artemisinin on breast cancer cell line. New Cellular and Molecular Biotechnology Journal. 2014;4:99-103.

12. Hage M, Zantout MSM, Azar ST: Thyroid disorders and diabetes mellitus.J Thyroid Res 2011, 2011:439463.

13. Proces S, Delgrange E, VanderBorght TV, Jamart J, Donckier JE. Minor alterations in thyroid function tests associated with diabetes mellitus and obesity in outpatients without known thyroid illness. Acta Clin Belg 2001 Mar-Apr; 56 (2): 86-90

14. Perros P, McCrimmon RJ, Shaw G, Frier BM: Frequency of thyroid dysfunction in diabetic patients: value of annual screening.Diabet Med 12:622-627, 1995

15. Papazafiropoulou A, Sotiropoulos A, Kokoloki A, Kardara M, Stamataki P,e Pappas S: Prevalence of thyroid dysfunction among greek type 2diabetic patients attending an outpatient clinic. J Clin Med Res 2010,2:75-78.

16. Adler SM, Wartofsky L, 2007 The nonthyroidal illness syndrome. Endocrinol Metab Clin North Am 36: 657-672.

17. Umpierrez GE, Latif KA, Murphy MB, Lambert HC, Stentz F, Bush A, et al: Thyroid dysfunction in patients with type 1 diabetes. Diabetes Care 2003,

26:1181-1185.

18. Prazny, M., Skrha, J., Limonova, Z., et al. (2005) Sceening for associated autoimmunity in type 1 diabetes mellitus with respect to diabetes control. Physiological Re- search, 54, 41-48.

19. Montovani, R.M., Montovani, L.M. and Dias, V.M. (2007) 
Thyroid autoimmunity in children and adolescents with type 1 diabetes mellitus: Prevalence and risk factors. Jour- nal of Pediatric Endocrinology \& Metabolism, 20, 669- 675.

20. Gonzalez, G.C., Capel, I., Rodriguez-Espinosa, J., et al. (2007) Thyroid autoimmunity at onset of type 1 diabetes as a predictor of thyroid dysfunction. Diabetes Care, 30, 1611-1612. doi:10.2337/dc07-1292

21. Hanukoglu, A., Mizrachi, A., Dalal, I., et al. (2003) Extrapancreatic autoimmune manifestations in type 1 diabetes patients and their first-degree relatives. Diabetes Care, 26, 1235-1240. doi:10.2337/diacare.26.4.1235

22. Catia Cristina Silva Sousa Vergara Palma,Marco Pavesi,Veronica Guedes Nogueira,et al Prevalence of thyroid dysfunction in patients with diabetes mellitus,Diabetology \& Metabolic Syndrome 2013, 5:58

23. Tunbridge WMG, Evered DC, Hall R, Appleton D, Brewis M, Clark F, et al: The spectrum of thyroid disease in a community: the Wickham survey. Clin Endocrinol (Oxf ) 1977, 7(6):481-493

24. Perros P, McCrimmon RJ, Shaw G, Frier BM: Frequency of thyroid dysfunction in diabetic patients: value of annual screening. Diabetes Med 1995, 12(7):622-627.

25. Hallowell JG, Staehling NW, Dana Flanders W, Hannon WH, Gunter EW, Spencer CA, Braverman LE: Serum TSH, T4, and Thyroid Antibodies in the United States Population (1998 to 1994): National Health and Nutrition Examination Survey (NHANES III). J Clin Endocrinol Metab 2002, 87(2):489-499.

26. Canaris GJ, Manowitz NR, Mayor G, Chester RE: The Colorado thyroid disease prevalence study. Arch Intern Med 2000, 160(4):526-534.

27. Hansen D, Bennedbaek FN, Hansen LK, Hoier-Madsen M, Jacobsen BB, Hegedüs L: Thyroid function, morphology and autoimmunity in young Patients with insulin-dependent diabetes mellitus. Eur J Endocrinol 1999, 140:512-518

28. Jaeger C, Petzoldt R, Hatziagelaki E, Bretzel RG: Comparative analysis of organ-specific autoantibodies and celiac disease-associated antibodies in type 1 diabetic patients, their first-degree relatives, and healthy control subjects. Diabetes Care 2001, 24:27-32.

29. Kalicka-Kasperczyk, A., Dziatkowiak, H., Bratnik-Mi- kuta, A., et al. (2002) Thyroid peroxidase antibodies and thyroid disease in children and adolescents with newly diagnosed type 1 diabetes. Przegląd Lekarski, 59, 509- 513.

30. Goodarzi MT, Mohammadian M, Borzouei Sh,et al (2014). Association between Plasma Cholesteryl Ester Transfer Protein activity and Lipid profiles in Metabolic Syndrome in an Iranian Population. Int Res J Biological Sci.3;89-90.

31. Mohammadian M, Toofani Milani A, Hassas M R,et al (2015). Evaluation of Serum Iron, Zinc and Their Relationships with Glycemic Control Status in Iranian Elderly Women with Type 1 Diabetes Mellitus. Journal of Pharmacy and Pharmacology. 3;411-416.

32. Zeynali M S, Mohammadian M, Kheradmand F et al (2018). A molecular basis for the synergy between 17 allylamino 17 demethoxy geldanamycin with Capecitabine and Irinotecan in human colorectal cancer cells through VEFG and MMP-9 gene expression. Gene. pii: S0378-1119(18)31050-3.

33. Mohammadian M, Zeynali S, Azarbaijani AF, Khadem Ansari MH, Kheradmand F. Cytotoxic effects of the newlydeveloped chemotherapeutic agents 17-AAG in combination with oxaliplatin and capecitabine in colorectal cancer cell lines. Research in Pharmaceutical Sciences.;12(6): 2017:517-525. doi:10.4103/1735-5362.217432.

34. Rostaminasab S, Noori S, Yaghmaei B, Rostaminasab Dolatabad M, Toofani Milani A, Mohammadian M.
Antitumor Immunostimulatory Effect of Sitosterol from Salvia atropatana on Tumor bearingmice. Adv Biores. 6(5), (2015) : 133-140

35. Mohamadi N, Kazemi SM, Mohammadian M, et al. Toxicity of Cisplatin-Loaded Poly Butyl Cyanoacrylate Nanoparticles in a Brain Cancer Cell Line: Anionic Polymerization Results. Asian Pacific Journal of Cancer Prevention : APJCP.;18(3): (2017):629-632. doi:10.22034/APJCP.2017.18.3.629.

36. Sajjadiyan S Z, Ghadernejad H, Toofani Milani A, Mohammadian M, Abdolahpour S, Taslimi S MoradiSardareh, H, Afrisham R, Kooti W. Preparation of silibinin loaded pegylatedniosomal nanoparticles and investigation of its effect on MCF-10A human breastcancer cell line. Der Pharmacia Lettre.8 (16): (2016):70-75

37. Arshad Z, Rezapour-Firouzi S, Mohammadian M, et al(2018). The Sources of Essential Fatty Acids for Allergic and Cancer Patients; a Connection with Insight into Mammalian Target of Rapamycin: A Narrative Review. Asian Pac J Cancer Prev. 19(9):2391-2401.

This work is licensed under a Creative Commons AttributionNon Commercial 4.0 International License. 